\title{
Investigación en
} comunicación:

Síntesis:

Se analiza la necesidad de articular los planteamientos de los Estudios Culturales y de la Economía Política de la Comunicación para comprender los fenómenos mediáticos actuales.

La discusión se presenta en un momento en

el que muchos autores de la comunicación parecieran rechazar el segundo paradigma, dada la indudable importancia que ha tenido

el paradigma culturalista en el estudio de la comunicación. Para sustentar la tesis central del presente escrito se examinan las diferencias entre las siguientes dicotomías: orden simbólico/orden social, hegemonía/ideología, y representación simbólica/ representación social.

Palabras clave: economía política, estudios culturales, representación, comunicación, poder.

Synthesis:

The need to articulate the proposals of the Cultural Studies and of the Political Economy of the Communication it is analyzed in order to understand the media present-day phenomena.

The discussion shows up in a moment that many communications authors seem to refuse the second paradigm given the unquestionable impressiveness that the culturalist paradigm has

had in the study of communication. In order to uphold the central thesis of this present text it is examined the differences between the following

dichotomies: Symbolic order/social order, hegemony/ideology, and symbolic representation/ social performance.

Key Words: political economy, cultural studies, representation, communication, power.

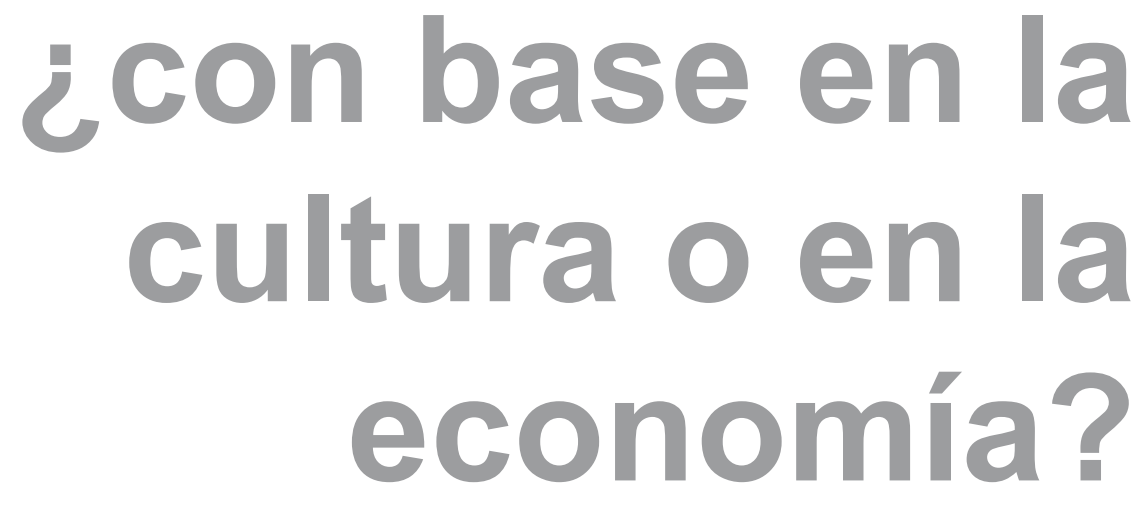

Adriana María Ángel Botero Comunicadora Social y Periodista, Magíster en Comunicación Educativa.

Directora del Centro de Investigaciones de la Comunicación Facultad de Comunicación Social y Periodismo, Universidad de Manizales. e-mail: cifc@umanizales.edu.co Fecha de recepción: 04-03-08 Fecha de aprobación: 18-06-08

\section{Introducción}

\section{Al revisar la reciente producción teórica de la comunicación se encuentra un marcado énfasis de}

los investigadores y académicos en resaltar la importancia de la cultura para entender los procesos comunicativos. Tanto los Estudios Culturales como la llamada Teoría Latinoamericana de la Recepción 
Activa han planteado, con ayuda de la antropología, una definición de cultura más amplia en la que se puede incluir el conjunto de prácticas ordinarias de la vida cotidiana.

En este intento por explicar la comunicación desde marcos culturales, sin embargo, se han olvidado otros campos del conocimiento que históricamente han sido fundamentales para entender la comunicación. En este escrito se pretende entonces recordar una de esas fuentes disciplinares olvidadas como lo es la economía política y argumentar por qué la cultura no debe ser el único espacio para pensar la comunicación.

En primer lugar, se revisará rápidamente la historia de la tradición teórica de la comunicación para encontrar el momento en el que surge el interés por lo cultural. En segundo lugar, se expondrán los planteamientos olvidados de la Economía Política de la Comunicación. Para terminar, se anotará por qué ninguno de estos dos enfoques (el económico y el cultural), por sí solos, son suficientes para analizar la comunicación de manera integral y se mostrarán algunos riesgos que se corren al tratar de investigar bajo un único paradigma. No sobra prevenir al lector y advertirle que no es viable desarrollar a fondo, en este escrito, el tema que se propone, pero que sí es posible blandir algunos argumentos generales en torno al mismo.

\section{Relación cultura-comunicación}

A los investigadores latinoamericanos de la comunicación se les atribuye (o ellos mismos se atribuyen) la idea original de articular categorías culturales al estudio de los procesos comunicativos. No obstante, esta atribución requiere un análisis cuidadoso porque al revisar la tradición teórica de la comunicación se encuentra que otros investigadores, no latinoamericanos ni actuales, se han preocupado por articular las concepciones culturales con las comunicativas. Los desarrollos, como sucede en cualquier campo del conocimiento, son lentos y están fuertemente influenciados por los contextos de las épocas en que se producen.

Un primer antecedente teórico de la relación entre cultura y comunicación puede encontrarse en los planteamientos hechos por los autores de la Escuela de Frankfurt ${ }^{1}$ para quienes la empresa capitalista es la encargada de producir, de manera masiva, productos simbólicos para la sociedad de masas. A pesar de ser simbólica, la producción no es considerada por los teóricos críticos, como producción de cultura legítima en la medida en que no nace de un campo, sino que obedece a la traducción estereotipada ${ }^{2}$ de un modelo que fue exitoso en el mercado y que, según los intereses capitalistas e industriales, valdría la pena reciclar para repetir. De esta manera, la Escuela de Frankfurt retoma el problema de la cultura para asegurar que ésta se degrada y pierde su "aura"3 en la medida en que se produce masivamente y gracias a la serialización.

Con ello queda claro que desde la teoría Crítica, la cultura se refiere a la producción artística, y los medios de comunicación de masas, como industrias culturales, nada tienen que ver con la producción de arte o de cultura legítima, sino que éstos producen mercancías para el consumo de una sociedad de

\footnotetext{
1 JAY, Martín, La imaginación dialéctica: Una historia de la Escuela de Frankfurt, Madrid, Taurus, 1986.

2 ADORNO, Theodor y HORKHEIMER, Max, "La industria cultural"

en: Varios autores. Industria cultural y sociedad de masas, Caracas, Monte Ávila Editores, 1992, págs. 170-180.

${ }^{3}$ BENJAMIN, Walter, "El arte en la época de su reproducción mecánica”, en: CURRAN, James; GUREVITCH, Michael y WOOLLACOT, Janet, Sociedad y comunicación de masas, México, Fondo de Cultura económica, 1981, págs. 433-460.
} 
masas inculta. Hasta este momento de la historia no se piensa aún en los marcos culturales que podrían explicar el consumo cultural.

Una concepción radicalmente diferente de cultura se encuentra en los Estudios Culturales donde ésta ya no es entendida como producción estética elaborada por las élites ${ }^{4}$, sino como una práctica integrada y social que incluye el conjunto de los comportamientos cotidianos de las personas ordinarias ${ }^{5}$. A diferencia de la Escuela de Frankfurt, los Estudios Culturales no conciben el consumo de productos culturales en términos de recogimiento, sensibilidad y conocimiento, sino que plantean la cultura como el ámbito que abarca la totalidad de las prácticas que generen procesos de significación.

Como puede observarse, se trata de dos concepciones de cultura diferentes que, según el contexto teórico e histórico, se retoman para pensar la comunicación. Así, frente al problema del papel que desempeñan las industrias culturales en la sociedad, la tradición alemana llega a conclusiones distintas de las que plantea la tradición inglesa. Desde la primera, es decir, desde la Escuela de Frankfurt, se abordan las industrias culturales como empresas capitalistas responsables de la masificación y la alienación de una sociedad de masas homogénea; desde la segunda, esto es, desde los Estudios Culturales, el problema de la industria cultural se enfoca hacia la representación cultural que hacen los medios de comunicación y a los marcos simbólicos a partir de los cuales los receptores re-construyen y plantean lecturas negociadas y oposicionales.

\footnotetext{
${ }^{4}$ BRHN JENSEN, Klaus, La semiótica social de la comunicación de masas, Barcelona, Bosch, 1997, pág. 99.

${ }^{5}$ GRANDI, Roberto, Texto y contexto en los medios de

comunicación, Barcelona, Bosch, 1995, pág. 95.
}

Esta visión no es radicalmente distinta a la expuesta por los teóricos latinoamericanos quienes, al igual que los investigadores de los Estudios Culturales ingleses han estudiado los procesos comunicativos desde los marcos culturales de los receptores. Tanto desde los Estudios Culturales como desde las "teorías" latinoamericanas se puede identificar un interés común por el estudio de la cultura en temas específicos como el melodrama (Modleski ${ }^{6}$ y Martín Barbero ${ }^{7}$ ), los usos sociales de la televisión (Martín Barbero ${ }^{8}$ y James Lull19), la "muerte" de la audiencia (Fiske ${ }^{10}$ y Lozano ${ }^{11}$ ), el consumo cultural (Ang y García-Canclini ${ }^{2}$ ), entre muchos otros ejemplos.

De hecho, en la introducción a la compilación sobre el consumo cultural en América Latina, Guillermo Sunkel ${ }^{13}$ expone cómo los enfoques latinoamericanos han tenido dos "desplazamientos teórico-metodológicos" similares a los que se dieron en los Estudios Culturales. Dichos desplazamientos van del mensaje entendido como estructura ideológica a la recepción crítica y, de ésta, al interés por el consumo. En cada momento los énfasis han sido distintos. Así, mientras que, bajo el paradigma de la recepción activa se argumentó

${ }^{6}$ CLANCY, Kim y MODLESKI Tania, "Amar plenamente: fantasías de producción de masas para mujeres" en: BARKER, Martín, BEEZER, Anne (Eds), Introducción a los Estudios Culturales. Barcelona,

Bosch, 1997, págs. 133-147.

${ }^{7}$ MARTÍN-BARBERO, Jesús y MUÑOZ, Sonia (Coord.), Televisión y melodrama, Bogotá, Tercer Mundo Editores, 1992.

${ }^{8}$ MARTÍN-BARBERO, Jesús, "Recepción de medios y consumo cultural”, en: SUNKEL, Guillermo (Comp), El consumo cultural en América Latina, Bogotá, Convenio Andrés Bello, 1999.

${ }^{9}$ GRANDI, Roberto, ob. cit., págs. 159-161.

${ }^{10}$ Ibíd., págs. 239-241.

${ }^{11}$ LOZANO, Elizabeth, "Del sujeto cautivo a los consumidores nomádicos", en: SUNKEL, Guillermo (Comp), ob. cit., págs. 50-67.

${ }^{12}$ CANCLINI, Néstor, "El consumo cultural: una propuesta teórica", en: SUNKEL, Guillermo (Comp.), ob. cit., págs. 26-49.

${ }^{13}$ SUNKEL, Guillermo (Comp.), ob. cit., págs. XI-XXIX. 
la necesidad de educar a los receptores y hacer de ellos, sujetos reflexivos, en la actualidad se resalta la importancia de estudiar los lugares, objetos, procesos, necesidades y contextos del consumo cultural. Nada radicalmente diferente a la investigación que miembros de los Estudios Culturales están haciendo en Australia, Europa Continental, Inglaterra y Estados Unidos ${ }^{14}$.

De esta manera, la fuente y estructura fundamental de los Estudios Culturales y de los enfoques latinoamericanos es la misma: la cultura. Ello no implica que los desarrollos investigativos no varíen en la medida en que se trata de contextos sociales diferentes; tampoco implica que los latinoamericanos no hayan planteado conceptos novedosos como los de mediación o televidencia, pero estas categorías no constituyen una novedad absoluta para la comunicación, pues las ideas que refieren, se pueden relacionar con otros conceptos. No es éste el lugar para desarrollar el argumento; sin embargo, es necesario plantearlo para continuar con el desarrollo de la premisa central de este escrito.

Hasta acá se ha dicho que recientemente (desde los años 70 en Europa y desde los 80 en América Latina) se ha renovado el interés por el estudio de la cultura para comprender los procesos comunicativos. También se ha aclarado que este interés no es ni absoluta ni primordialmente latinoamericano, sino que su surgimiento puede situarse desde la elección de Stuart Hall como director del Centre for Contemporany Cultural Studies de la Universidad de Birmingham en Inglaterra desde 1969 hasta 1979.

\footnotetext{
${ }^{14}$ Ver libros como: SILVERSTONE, Roger y HIRSCH, Eric, Los efectos de la nueva comunicación, Barcelona, Bosch, 1996;

BARKER, Martín, BEEZER, Anne (Eds), Introducción a los Estudios Culturales, Barcelona, Bosch, 1997.
}

\section{La economía definida como cultura}

La atención exagerada en el ámbito de la cultura para el estudio de la comunicación ha traído como consecuencia el olvido de otros desarrollos teóricos fundamentales que ponen de relieve los contextos político-económicos tanto de la emisión como de la recepción de mensajes de los medios de comunicación. Dichos desarrollos se relacionan, específicamente, con los hechos por la llamada Economía Política de la Comunicación ${ }^{15}$ con sus vertientes europea y latinomericana. La primera, plateada por autores como Nicolás Garnham, Peter Golding, James Curran, Graham Murdock, entre otros; y, la segunda, identificada con Armand Mattelart, Eliseo Verón, Antonio Pascuali, Luis Ramiro Beltrán, entre otros muchos autores olvidados desde la irrupción de la llamada corriente de la Recepción Activa de corte más pluralista y liberal ${ }^{16}$.

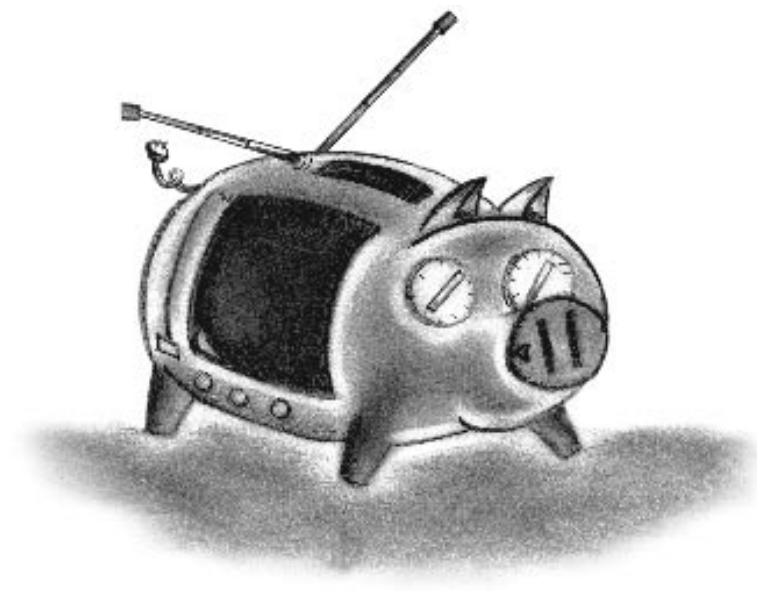

\footnotetext{
${ }^{15}$ MATTELART, Armand y Michélle, Historia de las teorías de la comunicación, Barcelona, Paidos, 1996; BELTRÁN, Luis Ramiro, Investigación sobre comunicación en Latinoamérica, La Paz, Plural Editores, 2000; y FERGUSON, Marjorie y GOLDING, Peter, Economía política y estudios culturales, Barcelona, Bosch, 1998.
} 
Vale la pena aclarar que el enfoque de la teoría Crítica de la Escuela de Frankfurt no es equivalente al de la Economía Política de la Comunicación. Se trata de dos teorías de la comunicación diferentes: la primera surge en Alemania en la década de los 30 con Horkheimer y apunta, como ya se ha dicho, al problema de la producción de la industria cultural que enajena y masifica. La Economía Política de la Comunicación, por su parte, surge en Inglaterra y más tarde en América Latina hacia la década de los 60 preocupada por los problemas del libre flujo de la Información, el imperialismo y la dependencia cultural.

A partir de la exposición de los temas investigados desde la Economía Política de la Comunicación se puede dar una idea de los intereses de conocimiento que se persiguen desde este modelo. En el campo de los emisores es frecuente la pregunta por la propiedad de los medios, los intereses de los emisores y las relaciones entre el campo de la comunicación y el de la economía política; desde el mensaje predomina el estudio de la representación y de los discursos dominantes que naturalizan la desigualdad social al ocultar

${ }^{16}$ CURRAN, James, "EI nuevo revisionismo en los estudios culturales”, en: CURRAN, James, GUREVITCH, Michael y WOOLLACOT, Janet, ob.cit., págs. 383-415.

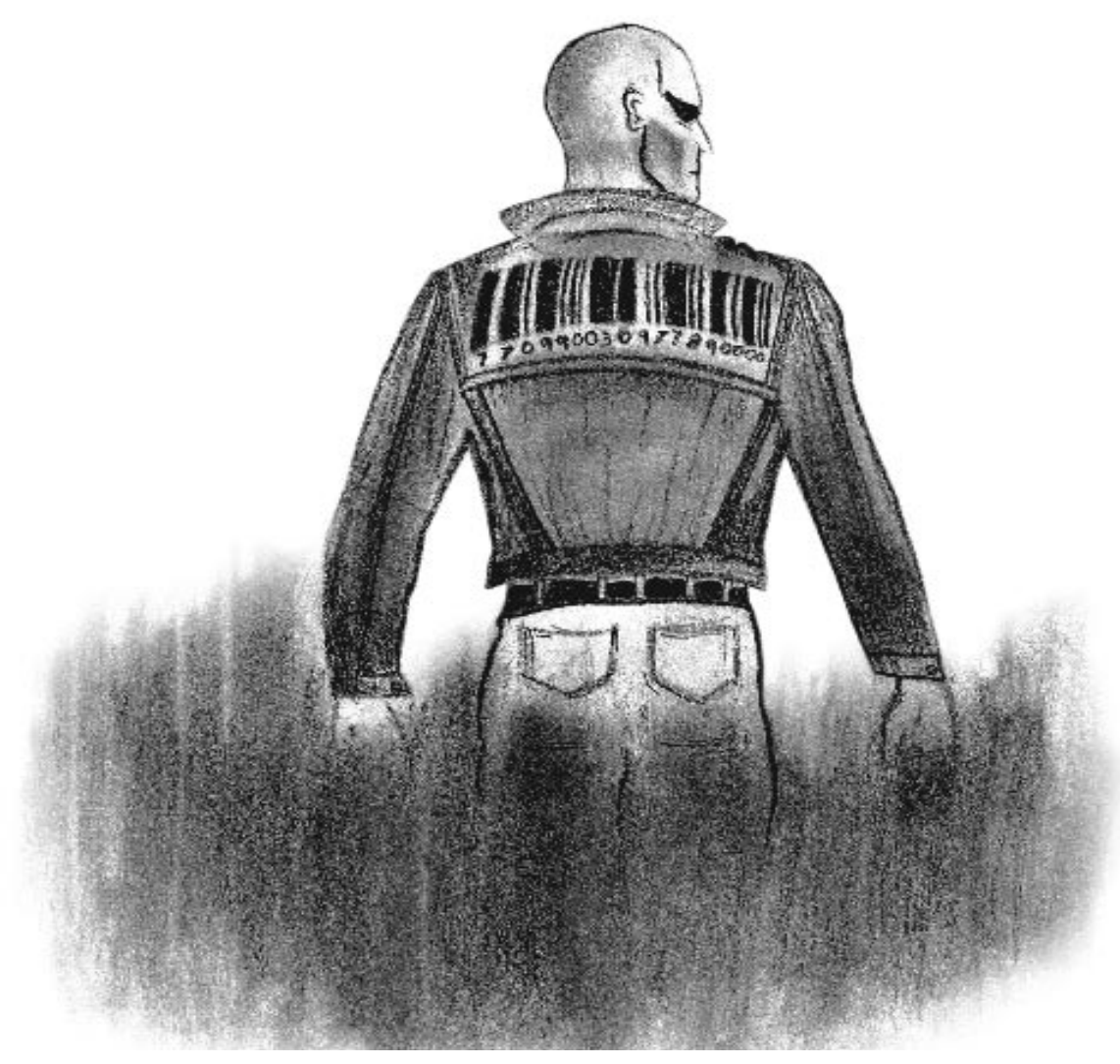

contradicciones y filtrar ideologías; desde los receptores se investiga cómo los sistemas de producción generan formas de decodificación específicas y tipos de audiencias particulares.

La economía, como puede observarse, es el tema base y estructural de este enfoque teórico de la comunicación, que encuentra la explicación a los procesos comunicativos en los sistemas de producción y distribución de los mensajes de los medios masivos.

Para ello incorpora categorías, bastante despreciadas en 
la actualidad, como las de marxismo, economía de la cultura, desarrollo y subdesarrollo, ideología, entre otras.

Sobre esto Murdock afirma: "La ambición principal de la economía política crítica es trazar detalladamente cómo la dinámica central del capitalismo, y los equilibrios cambiantes entre los mercados y la disposición pública moldean la elaboración y captación de significado de la vida cotidiana a cada nivel a través de los múltiples marcos de producción y consumo -y cómo facilitan, comprometen o bloquean la construcción de una verdadera cultura democrática común"; 17 o como lo expresa más adelante en el mismo texto: "Conocer qué tipos de sistemas de producción generan qué tipos de audiencias y formas de decodificación puede que ayude a los estudios de la recepción a entender mejor cómo las audiencias interactúan con los textos dentro de sistemas muy determinados"18

Con el resaltado fracaso del marxismo y de la Modernidad y con la llegada del posmarxismo y la posmodernidad, este enfoque económico de la comunicación es tema central de críticas cuando de discutir las dinámicas operativas de los medios de comunicación de masas se trata.

Esta dualidad citada es el panorama de la confrontación y de la concepción dicotómica en la que creen verse muchos de los investigadores de la comunicación, esto es, frente a un dualismo que les impone escoger entre abordar la comunicación desde la cultura $\mathrm{O}$ hacerlo desde la economía política. La mayoría de las veces está bien visto que el estudioso se decida

\footnotetext{
17 MURDOCK, Graham, "Comentarios de base: las condiciones de la práctica cultural”, en: FERGUSON, Marjorie y GOLDING, Peter (Eds), ob.cit., pág. 172.

18 Ibid., pág. 202
}

por recorrer el camino de lo cultural con lo que se cae en una visión lineal de la historia teórica de la comunicación, según la cual, unos enfoques van superando a otros, como si pasaran de moda, por lo tanto no es válido retomar planteamientos teóricos de los funcionalistas, estructuralistas o críticos porque éstos ya fueron superados por la visión culturalista de la comunicación.

Una concepción dicotómica de este tipo trae como consecuencia la investigación que se está produciendo en la actualidad: marcadamente centrada en lo cultural y desprovista de categorías y factores económicos. Ello trae, a su vez, otra consecuencia específica que tiene que ver con la tendencia de los investigadores a definir categorías que son eminentemente económicas en términos culturales o de considerar los conceptos culturales como suficientes para explicar todos los fenómenos de la sociedad. Así, de la lectura que, entre líneas se hace de algunos autores, puede notarse cómo equiparan el concepto de orden simbólico con el de orden social; el de hegemonía por el de ideología, el de representación simbólica por el de representación social, entre otros. Con ello se reduce la lectura de la sociedad al ámbito exclusivamente cultural. Vale la pena profundizar en algunos de estos ejemplos:

1. Tanto los Estudios Culturales como los planteamientos latinoamericanos sobre la comunicación rechazan el marco marxista para explicar los fenómenos comunicativos. Así, desprecian el análisis de la ideología de los emisores filtrada en los mensajes y prefieren, en cambio, trabajar desde el concepto de las ideologías vistas en un sentido absolutamente diferente del original. De hecho, mientras que la Economía Política atribuye el mantenimiento de la sociedad a la Ideología, los Estudios Culturales consideran que los sujetos tienen y son conscientes de sus propias ideologías. En el primer 
caso la ldeología, entendida como el conjunto de ideas dominantes de una sociedad, naturaliza las relaciones sociales al establecer ciertas ideas como generales, racionales y de vigencia absoluta. Es por ella que los sectores dominados mantienen el modo de producción, satisfacen los intereses de las élites y aseguran el equilibrio social gracias a una falsa conciencia que les hace sentir los intereses dominantes como propios.

En el segundo caso, esto es, desde la perspectiva de los Estudios Culturales, ya no se piensa en "La Ideología", sino en "Las Ideologías" entendidas como las concepciones de mundo que se manifiestan implícitamente en todas las actividades individuales y colectivas ${ }^{19}$. Stuart Hall, por citar sólo a un autor, la define como sistemas de representación compuestos por ideas, mitos, significados o conceptos, a partir de los cuales los sujetos viven sus relaciones imaginarias ${ }^{20}$.

Dicha transición de la connotación político-económica del término a una cultural-social está relacionada con la influencia del posmarxismo y el posfordismo que, en términos generales, declaran la muerte del marxismo con el triunfo del capitalismo, el auge de los modelos neoliberales, la llegada de la Sociedad de la Información, el llamado "fin de la historia" y la muerte de los Estados-Nación.

Este es uno de los casos más representativos y frecuentes en los que un concepto que en su origen es eminentemente económico se resignifica en términos culturales. Ello hace que al estudiar las ideologías implícitas

19 ESTEINOU MADRID, Francisco Javier, Los medios de comunicación y la construcción de la hegemonía, México, Trillas, 1992, pág. 149. ${ }^{20}$ HALL, Stuart, "Significado, representación, ideología”, en: CURRAN, James; MORLEY, David y WALKERDINE, Valerie (Comp), Estudios culturales y comunicación, Barcelona,

Paidos, 1998, pág.45. en los procesos comunicativos, los investigadores no se pregunten por temas como la propiedad, los intereses o las clases, sino por los significados, los mitos o las concepciones de mundo, todos ellos claramente pertenecientes al orden cultural.

2. Otro ejemplo, en el que se demuestra la manera como las recientes teorías de la comunicación (y las ciencias sociales en general) resignifican algunos conceptos económicos desde el punto de vista cultural tiene que ver con la representación social y simbólica ${ }^{21}$.

La representación como objeto de estudio ha sido planteada, específicamente, por los Estudios Culturales. Sin embargo, en el ámbito latinoamericano de los estudios culturalistas hechos por Martín-Barbero o Guillermo Orozco, se ha hecho énfasis en el análisis de la representación simbólica, esto es, de las sensibilidades, códigos y 'formas de ser' de los sujetos reflejados por los medios. Para estos, y otros autores ${ }^{22}$, la tarea de los medios consiste en representar las diferentes subculturas de manera que ninguna se invisibilice. Esto, sin embargo, hace referencia, sólo al aspecto simbólico de la representación dejando a un lado, el ámbito social que tiene que ver con la responsabilidad de los medios de representar a los receptores no sólo desde sus características culturales, sino también desde sus intereses y necesidades políticas y económicas.

En la medida en que se toma a la representación simbólica como única función de los medios de

21 ÁNGEL, Adriana, "Deficiencias del modelo comunitario:

¿Responsabilidad de los medios o de la comunidad?", en: Revista

Escribanía No. 13, Manizales, junio-diciembre de 2004, Universidad de Manizales, págs. 51-63.

${ }^{22}$ Ver autores como Omar Rincón, Rossana Reguillo, Adriana D'elia

Mendoza, Jesús Martín-Barbero, Guillermo Orozco. 
comunicación se les deja de pensar como instituciones que cumplen funciones sociales tales como la vigilancia del entorno y la conexión de los campos a través de los flujos informativos. Estas dos últimas funciones no obedecen ni al ámbito de las esferas culturales o de las matrices simbólicas de los sujetos, pero sí tienen que ver con la necesidad de contar con medios que ofrezcan, no sólo entretenimiento y representación de las identidades, sino también, información económica y política para la participación.

3. Otro de los conceptos "vaciado" de su original connotación económica es el orden social que recientemente se define o se hace equivaler al de orden simbólico en el marco, sobre todo, de las investigaciones sobre el mundo de las subculturas juveniles. Este tema del estilo de las subculturas ha preocupado, entre otros autores, a Dick Hebdige ${ }^{23}$, quien se ha interesado por el estudio de la gramática del estilo juvenil para develar el significado de la ropa, argot, música y rituales de estos grupos, pues es precisamente a través de elementos simbólicos que las subculturas buscan agredir el orden social y establecer una identidad cultural. Esto es posible, según explica el autor, gracias a que, a través de la ideología anónima se transgrede el orden simbólico y, con ello, el orden social.

Esta concepción muestra entonces cómo se hacen equivalentes los conceptos de orden social y simbólico. Existe, no obstante, una gran diferencia, entre resignificar, innovar o crear nuevos significantes en el ámbito cultural de los lenguajes y en modificar y cambiar el orden social, esto es, el modelo económico o político. Con la llamada resistencia de los jóvenes (rockeros o

${ }^{23}$ BEEZER, Anne, HEBDIGE, Dick, "Subcultura: El significado del estilo", en: BARKER, Martín y BEEZER, Anne (Eds), ob.cit., págs. 115-132. de cualquier tipo) se altera el orden simbólico, pero permanece intacto el social, fortalecido incluso con su indiferencia política. Con esta confusión, como explica Ancízar Narváez: "Por una parte, se refuerza la exclusión con la autoexclusión y, por otra, se despolitizan y se desideologizan los conflictos sociales, es decir, se despojan de su carácter estructural y se reducen a problemas técnicos, personales o, como se suele decir hoy, problemas de comunicación y convivencia"24.

4. Otro caso frecuente es el de la escasa distinción entre los conceptos de redistribución y reconocimiento. Martín-Barbero afirma: "la lucha por la vivienda, por los servicios de energía eléctrica y de agua, por un transporte mínimo y un mínimo de atención a la salud se inscribe en una realidad más integral, la de la lucha por la identidad cultural"25. Esa concepción, muestra otro de los casos más frecuentes en que un problema económico se aborda como problema cultural. Existe, una gran diferencia entre estos dos tipos de problemas que Nancy Fraser $^{26}$ explica diferenciando entre redistribución y reconocimiento. Ambas hacen referencia a las soluciones que se deben plantear frente a las injusticias culturales y económicas.

La injusticia se entiende desde Fraser como la desventaja de un grupo de personas frente a otro y es de dos tipos: socioeconómica y cultural o simbólica. La primera se relaciona con la injusticia política y económica, mientras que la segunda alude a los patrones sociales de interpretación y comunicación. Aunque en la práctica

${ }^{24}$ NARVÁEZ MONTOYA, Ancízar, "Multiculturalismo y mercado: Las puntas de la madeja", en: Revista Signo y Pensamiento, No. 46 Vol. XXIV, Bogotá, Pontificia Universidad Javeriana, 2005, pág. 33.

${ }^{25}$ MARTÍN-BARBERO, Jesús, De los medios a las mediaciones, Barcelona, Gustavo Gili, 1987, pág. 215.

${ }^{26}$ FRASER, Nancy, lustitia Interrupta, Bogotá, Siglo del Hombre Editores, 1997, págs. 17-54. 


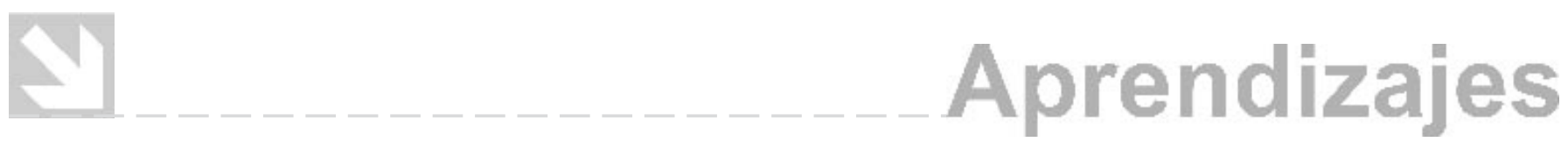

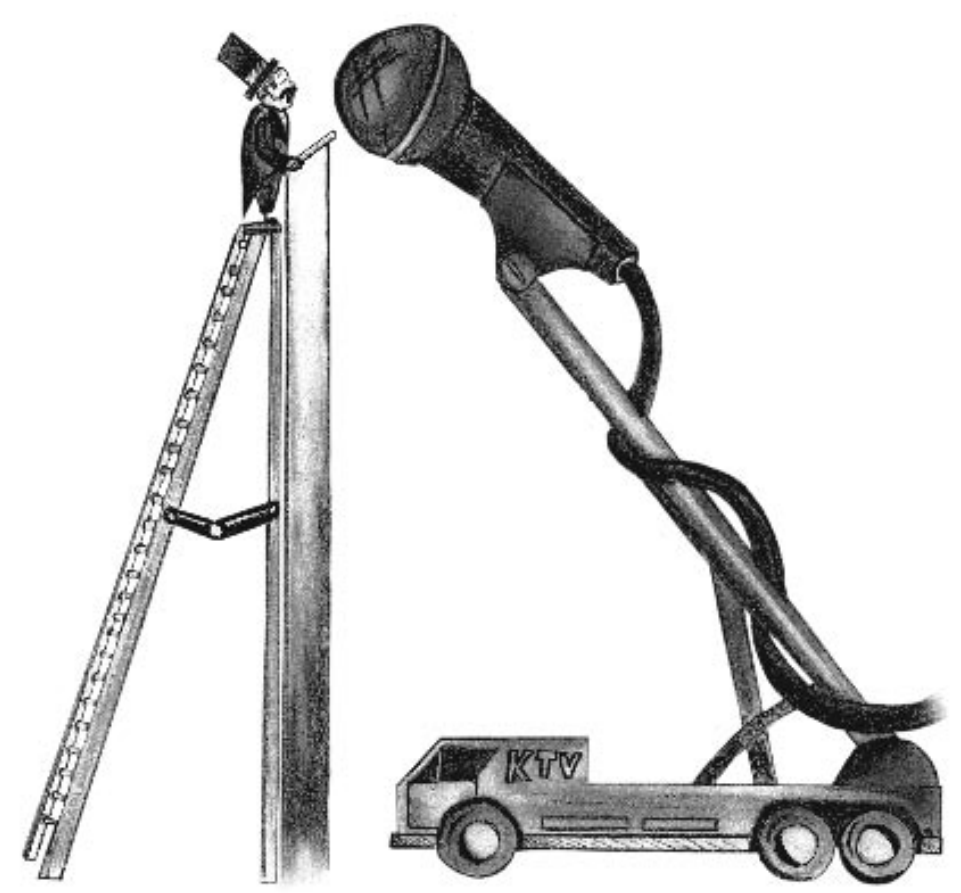

estas dos categorías no se puedan separar, resulta valioso hacerlo con fines analíticos para determinar en qué medida se entrecruzan; éste es el caso de las clases explotadas que, a pesar de que su problema es ante todo económico, deben sufrir también injusticias y juicios culturales. En el caso contrario, una injusticia que tenga origen cultural, ocurre exactamente lo mismo en la medida en que, como consecuencia de ese rechazo, se deben aceptar consecuencias en la estructura económica. La solución a los problemas de redistribución consiste en eliminar a los grupos o subculturas afectadas (al proletariado por ejemplo), mientras que en el caso del reconocimiento la solución está en integrar y aceptar ese grupo.
Por ello, no puede pensarse, como afirma MartínBarbero que la carencia del acceso a los servicios públicos sea un problema de reconocimiento de las identidades culturales. Murdock lo expresa de la siguiente manera: "La atención en la diferencia favorece una política cultural de reconocimiento, basado en torno a la demanda de ser escuchado y respetado, tiene muy poco o nada que decir sobre una política de redistribución que esté preocupada por asignar los recursos necesarios para una completa expresión y participación"27.

Sobre esta arbitrariedad en el uso de conceptos se sustentan también muchos de los comentarios (la mayoría de las veces desprovistos de confrontación empírica) de Omar Rincón quien asegura, en uno de sus escritos: "La economía determina los modos de producción de una sociedad y domina el escenario de lo llamado 'importante', pero genera muy poco sentido para la vida cotidiana. La cultura, por su parte, sirve mucho para la vida diaria, ya que interviene la economía para producir los modos de imaginación y desear de la gente"28.

Después de analizar los ejemplos anteriores, puede notarse cómo el énfasis en el estudio de la comunicación exclusivamente desde marcos culturales hace extraviar al investigador de la atención en las variables económicas. De esta manera, muchos autores tratan de explicar fenómenos sociales, económicos y políticos con categorías eminentemente culturales. Pero ni las ideologías, ni el orden simbólico, ni la representación simbólica o el reconocimiento son conceptos para

\footnotetext{
${ }^{27}$ MURDOCK, Garnham, ob.cit., pág. 170.

${ }^{28}$ RINCÓN, Omar, "No hay globalidad que valga sin localidad que sirva", en: PEREIRA, José Miguel y VILLADIEGO PRINS, Mirla, Comunicación, cultura y globalización, Bogotá, Centro Editorial Javeriano, 2003, pág. 119.
} 


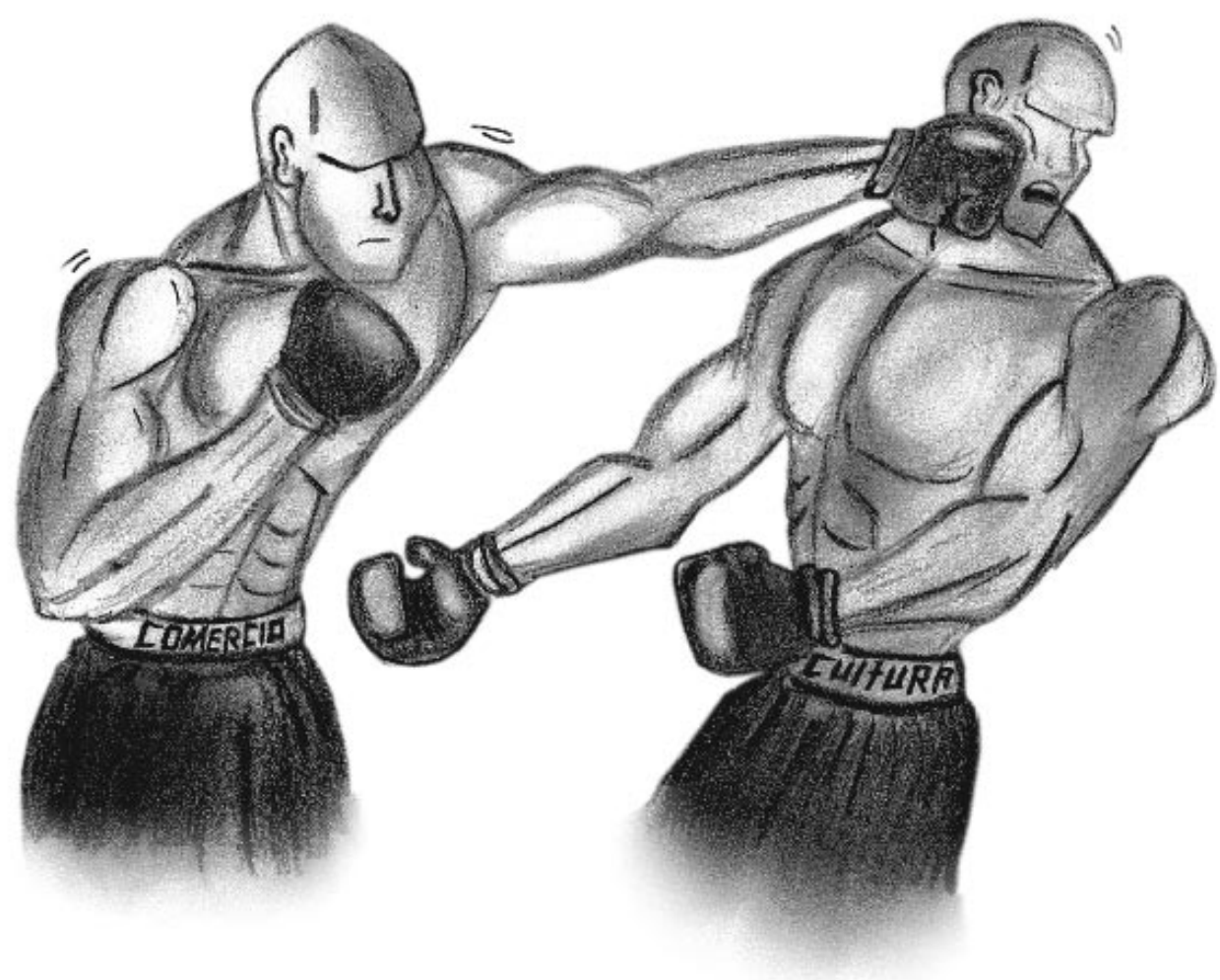

explicar fenómenos políticos y económicos como han tratado de hacer los investigadores de los Estudios Culturales y las teorías latinoamericanas.

La comunicación, en este panorama, no es sólo un proceso cultural, también hace parte de los campos económico y político que, como ha explicado Bourdieu, determinan en gran parte su naturaleza. De hecho, para Bourdieu: "el campo del periodismo tiene una particularidad: depende mucho más de las fuerzas externas que cualquier otro campo de la producción cultural... Depende directamente de la demanda, está sometido a la sanción del mercado, del plebiscito, incluso tal vez más que el campo político" 29.

Sin embargo, la comunicación no debe estudiarse solamente a partir de la economía política porque ello representaría otra visión reducida e incompleta del fenómeno desde el cual ya trabajaron muchos autores de corte marxista. Por ello, frente a esta supuesta dicotomía entre Economía Política de la Comunicaciónyal "determinismo superestructural" de los Estudios Culturales, se presenta entonces la necesidad de comprender la comunicación como un proceso enmarcado tanto en lógicas socio-económicas como en culturales. No se trata entonces de limitar el estudio de la comunicación al papel que juegan las matrices culturales, pero tampoco de restringirlo a un determinismo económico. En este sentido, tampoco es del todo conveniente asumir una visión "desarrollista" de las teorías de la comunicación, según la cual los enfoques actuales son los más pertinentes y los del pasado resultan obsoletos e inoperantes.

Una visión integral de la comunicación, esto es, una que articule factores culturales, económicos y políticos, impedirá al campo adoptar visiones liberales y pluralistas

${ }^{29}$ BOURDIEU, Pierre, Sobre la televisión, Barcelona, Anagrama, 1997, pág. 77. 
que centren la atención en los aspectos simbólicos del receptor y en su ilimitado poder de recepción en el llamado contexto de la democracia semiótica. Mattelart, precisamente desde la economía política, ha advertido las consecuencias de este problema: "la recepción y el individuo-consumidor ocupan un lugar central en la concepción neoliberal de la sociedad. No se trata de cualquier consumidor, sino de un consumidor llamado soberano en sus elecciones, en un mercado llamado libre... La opción por un interés exclusivo por el tema de la recepción destaca en el momento en que la hegemonía de los productores de los Estados Unidos está en el centro de las discusiones sobre el libre cambio y la libre circulación de los flujos en materia audiovisual que se desarrolla en el seno de instancias internacionales" ${ }^{\prime \prime}$.

\section{Bibliografía:}

BARKER, Martín, BEEZER, Anne (Eds), Introducción a los Estudios Culturales, Barcelona, Bosch, 1997.

BELTRÁN, Luis Ramiro, Investigación sobre comunicación en Latinoamérica, La Paz, Plural Editores, 2000.

BOURDIEU, Pierre, Sobre la televisión, Barcelona, Anagrama, 1997.

BRHN JENSEN, Klaus, La semiótica social de la comunicación de masas, Barcelona, Bosch, 1997.

CURRAN, James; GUREVITCH, Michael y WOOLLACOT, Janet, Sociedad y comunicación de masas, México, Fondo de Cultura económica, 1981.

CURRAN, James; MORLEY, David y WALKERDINE, Valerie (Comp), Estudios culturales y comunicación, Barcelona, Paidos, 1998.

FERGUSON, Marjorie y GOLDING, Peter, Economía política y estudios culturales, Barcelona, Bosch, 1998.

FRASER, Nancy, lustitia Interrupta, Bogotá, Siglo del Hombre Editores, 1997.

GRANDI, Roberto, Texto y contexto en los medios de comunicación, Barcelona, Bosch, 1995.

JAY, Martín, La imaginación dialéctica: Una historia de la Escuela de Frankfurt, Madrid, Taurus, 1986.

MARTíN-BARBERO, Jesús, De los medios a las mediaciones, Barcelona, Gustavo Gili, 1987.

${ }^{30}$ MATTELART, Armand y Michélle, ob.cit., pág. 103. 


\section{Megicariones}

MATTELART, Armand y Michélle, Historia de las teorías de la comunicación, Barcelona, Paidos, 1996.

NARVÁEZ MONTOYA, Ancízar, "Multiculturalismo y mercado: Las puntas de la madeja", en: Revista Signo y Pensamiento, No. 46, Vol. XXIV, Bogotá, Pontificia Universidad Javeriana, 2005.

SILVERSTONE, Roger y HIRSCH, Eric, Los efectos de la nueva comunicación, Barcelona, Bosch, 1996.

SUNKEL, Guillermo (Comp), El consumo cultural en América Latina, Bogotá, Convenio Andrés Bello, 1999. 